\title{
Glycaemic index values for commercially available potatoes in Great Britain
}

\author{
C. Jeya K. Henry ${ }^{1}$, Helen J. Lightowler ${ }^{1}$, Caroline M. Strik ${ }^{1}$ and Michael Storey ${ }^{2}$ \\ ${ }^{1}$ Nutrition and Food Science Group, School of Biological and Molecular Sciences, Oxford Brookes University, Gipsy Lane Campus, \\ Headington, Oxford OX3 OBP, UK \\ ${ }^{2}$ British Potato Council, 4300 Nash Court, John Smith Drive, Oxford Business Park South, Oxford OX4 2RT, UK
}

(Received 18 February 2005 - Revised 5 July 2005 - Accepted 11 July 2005)

\begin{abstract}
The glycaemic response to eight potato varieties commercially available in Great Britain was compared against a glucose standard in a non-blind, randomised, repeated measure, crossover design trial. Seventeen healthy subjects (three males, fouteen females), mean age 32 (SD 13 ) years and mean BMI $22 \cdot 3$ (SD $3.6) \mathrm{kg} / \mathrm{m}^{2}$, were recruited to the study. Subjects were served portions of eight potato varieties and a standard food (glucose), on separate occasions, each containing $50 \mathrm{~g}$ carbohydrate. Capillary blood glucose was measured from finger-prick samples in fasted subjects (0 min) and at $15,30,45,60,90$ and $120 \mathrm{~min}$ after the consumption of each test food. For each potato variety, the glycaemic index (GI) value was calculated geometrically by expressing the incremental area under the blood glucose curve (IAUC) as a percentage of each subject's average IAUC for the standard food. The eight potato varieties exhibited a wide range in GI values from 56 to 94 . A trend was seen whereby potatoes with waxy textures produced medium GI values, whilst floury potatoes had high GI values. Considering the widespread consumption of potatoes in Great Britain (933-1086 ger person per week), this information could be used to help lower the overall GI and glycaemic load of the diets of the British population.
\end{abstract}

Glycaemic index: Potato variety: Great Britain: Glycaemic load

The glycaemic index (GI), first introduced in 1981 (Jenkins et al. 1981), is a classification of the blood glucose-raising potential of the carbohydrates in foods. It is defined as the incremental area under the blood glucose curve (IAUC) of a $50 \mathrm{~g}$ carbohydrate portion of a test food expressed as a percentage of the response to $50 \mathrm{~g}$ carbohydrate of a standard (reference) food taken by the same subject, on a different day (Food and Agriculture Organization/World Health Organization, 1998).

Carbohydrate foods consumed in isoglucidic amounts produce different glycaemic responses depending on many factors, such as particle size, cooking and food processing, other food components (e.g. fat, protein, dietary fibre) and starch structure (Bjorck et al. 1994). The principle is that the slower the rate of carbohydrate absorption, the lower the rise of blood glucose level and the lower the GI value (Brand et al. 1991). Indeed, high GI foods are characterised by fast-release carbohydrate and higher blood glucose levels. A GI value $\geq 70$ is considered high, a GI value 56-69 inclusive is medium and a GI value $\leq 55$ is low, where glucose $=100$ (Brand-Miller et al. 2003).

The GI of foods may have important implications for the prevention and treatment of the major causes of morbidity and mortality in Western countries, including type 2 diabetes, CHD and obesity. Today, there is an important body of evidence to support the therapeutic potential of low-GI diets, not only in diabetes (Bjorck et al. 1994; Frost et al. 1994; Gilbertson et al. 2001; Augustin et al. 2002) but also in subjects with hyperlipidaemia (Jenkins et al. 1987a). In addition, low-GI foods have been associated with prolonged endurance during physical activity (Thomas et al.
1991), improved insulin sensitivity (Frost et al. 1998), reduced food intake (Holt et al. 1995; Warren et al. 2003) and increased colonic fermentation (Jenkins et al. 1987b; Wolever et al. 1992). More recent data support the preventive potential of a low-GI diet against the development of type 2 diabetes and CVD (Salmeron et al. 1997a,b; Frost et al. 1999; Meyer et al. 2000).

Potatoes generally have one of the highest GI values of any food, although some varieties appear to be lower than others. Published GI values are highly variable (Foster-Powell et al. 2002); however, it can be difficult to compare values as the variety of potato is rarely specified. It is necessary to clarify the GI of different varieties of potatoes as they are a major staple in Great Britain, contributing approximately $9 \%$ of total carbohydrate intake (National Statistics, 2004). In addition, there is widespread consumption of potatoes. Current figures show that average potato consumption (fresh and processed) in Great Britain ranges between 933-1086 g per person per week (National Statistics, 2004).

Previous research has shown no difference in GI values between three varieties of potato (Sebago, Pontiac and Desiree; Soh \& Brand-Miller, 1999). However, it was demonstrated that young or 'new' potatoes have a lower GI than more mature potatoes, which may be attributed to differences in starch structure. If a low-GI potato variety can be identified, it could be used to lower the overall GI and glycaemic load of the Western diet and thus decrease the risk of type 2 diabetes, CHD and obesity (Soh $e t$ al. 1999). There are limited data on the GI values of different varieties of commercially available potatoes within Great Britain. The aim of the current work is to investigate the glycaemic 

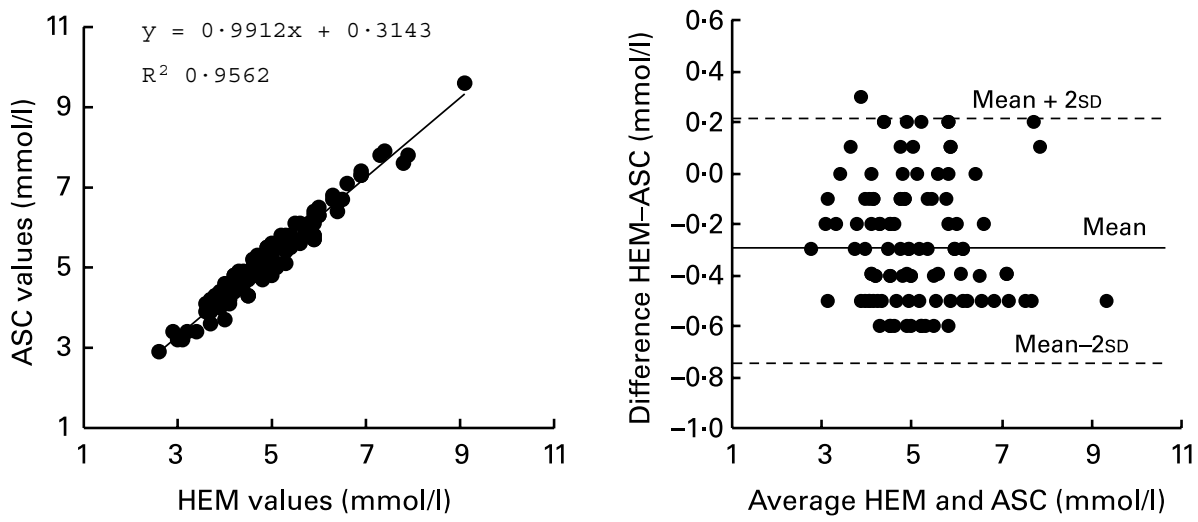

Fig. 1. Pearson regression and Bland-Altman analyses of blood glucose measurements between the Ascensia Contour (ASC) and HemoCue $201+$ analyser (HEM). For details of procedures, see this page.

response of eight varieties of potato commercially available in Great Britain.

\section{Methods}

\section{Subjects}

Seventeen healthy subjects (three male, fourteen female) were recruited through posters distributed throughout Oxford Brookes University in addition to announcements in lectures and through personal networks. Subjects were staff and students (undergraduate and postgraduate) from Oxford Brookes University and were moderately active, non-smoking men and women. Exclusion criteria were as follows: age $<18$ or $>55$ years; $\mathrm{BMI} \geq 30 \mathrm{~kg} / \mathrm{m}^{2}$; fasting blood glucose value $>6.1 \mathrm{mmol} / \mathrm{l}$. Mean age was 32 (SD 13) years and mean BMI was $22 \cdot 3$ (SD 3.6 ) $\mathrm{kg} / \mathrm{m}^{2}$. Ethical approval for the study was obtained from the University Research Ethics Committee at Oxford Brookes University. Subjects were given full details of the study protocol and the opportunity to ask questions. All subjects gave written informed consent prior to participation.

\section{Study protocol}

The protocol used was adapted from that described by Wolever et al. (1991) and is in line with procedures recommended by the Food and Agriculture Organization/World Health Organization (1998). To determine the GI of a food, tests should be repeated in six or more subjects, thus in the present study, for each test food, ten of the seventeen subjects recruited to the study were randomly selected. On the day prior to a test, subjects were asked to restrict their intake of alcohol and caffeine-containing drinks and to restrict their participation in intense physical activity (e.g. long periods at the gym, excessive swimming, running, aerobics). Subjects were also told not to eat or drink after 21.00 hours the night before a test, although water was allowed, in moderation.

\section{Test foods}

Eight potato varieties were tested: Maris Peer; Maris Piper; Desiree; Estima; Charlotte; Marfona; Nicola; King Edward. These varieties, all sourced from the British Potato Council, represent a diverse range of commercial varieties commonly consumed as fresh, rather than processed, potatoes in the UK.
The eight varieties were compared with a standard food (glucose) and were tested in equivalent carbohydrate amounts $(50 \mathrm{~g})$. The total solid and carbohydrate content of each potato variety was obtained from published values (Storey \& Davies, 1992; NIAB, 2004). In accordance with Food and Agriculture Organization/ World Health Organization (1998) recommendations, subjects tested each potato variety once and the standard food three times in random order on separate days, with at least a $1 \mathrm{~d}$ gap between measurements to minimise carryover effects. Subjects were studied in the morning after a $12 \mathrm{~h}$ overnight fast. To avoid starch retrogradation, potatoes were freshly prepared and cooked each morning. Potatoes were peeled, cut into quarters and then boiled in 1.5 litres unsalted water for $15 \mathrm{~min}$ until tender. Subjects consumed the standard food/test product at a comfortable pace, within $15 \mathrm{~min}$. The test products and the standard food were served with $200 \mathrm{ml}$ water. A further $200 \mathrm{ml}$ water was given during the subsequent $2 \mathrm{~h}$. Subjects were encouraged to keep physical activity to a minimum during the testing.

\section{Blood glucose measurements}

A qualified technician performed blood glucose measurements. A fasting blood sample was taken at $0 \mathrm{~min}$ and the standard food/test product was consumed immediately after this. Further blood samples were taken at 15, 30, 45, 60, 90 and $120 \mathrm{~min}$ after starting to eat.

Table 1. Incremental area under the blood glucose curves (IAUC) and glycaemic index (GI) values for each potato variety (Mean values with their standard errors)

\begin{tabular}{lrrrrr}
\hline & \multicolumn{2}{c}{ IAUC } & & \multicolumn{2}{c}{ GI value } \\
\cline { 2 - 3 } \cline { 6 - 6 } Potato variety & Mean & SEM & & Mean & SEM \\
\hline Maris Peer & 182 & 33 & & 94 & 16 \\
Maris Piper & 167 & 17 & & 85 & 4 \\
Desiree & 133 & 18 & & 77 & 17 \\
Estima & 143 & 13 & & 66 & 5 \\
Charlotte & 134 & 30 & & 66 & 5 \\
Marfona & 93 & 21 & & 56 & 3 \\
King Edward & 166 & 10 & & 75 & 10 \\
Nicola & 130 & 10 & & 59 & 7 \\
\hline
\end{tabular}

For details of procedures, see this page. 

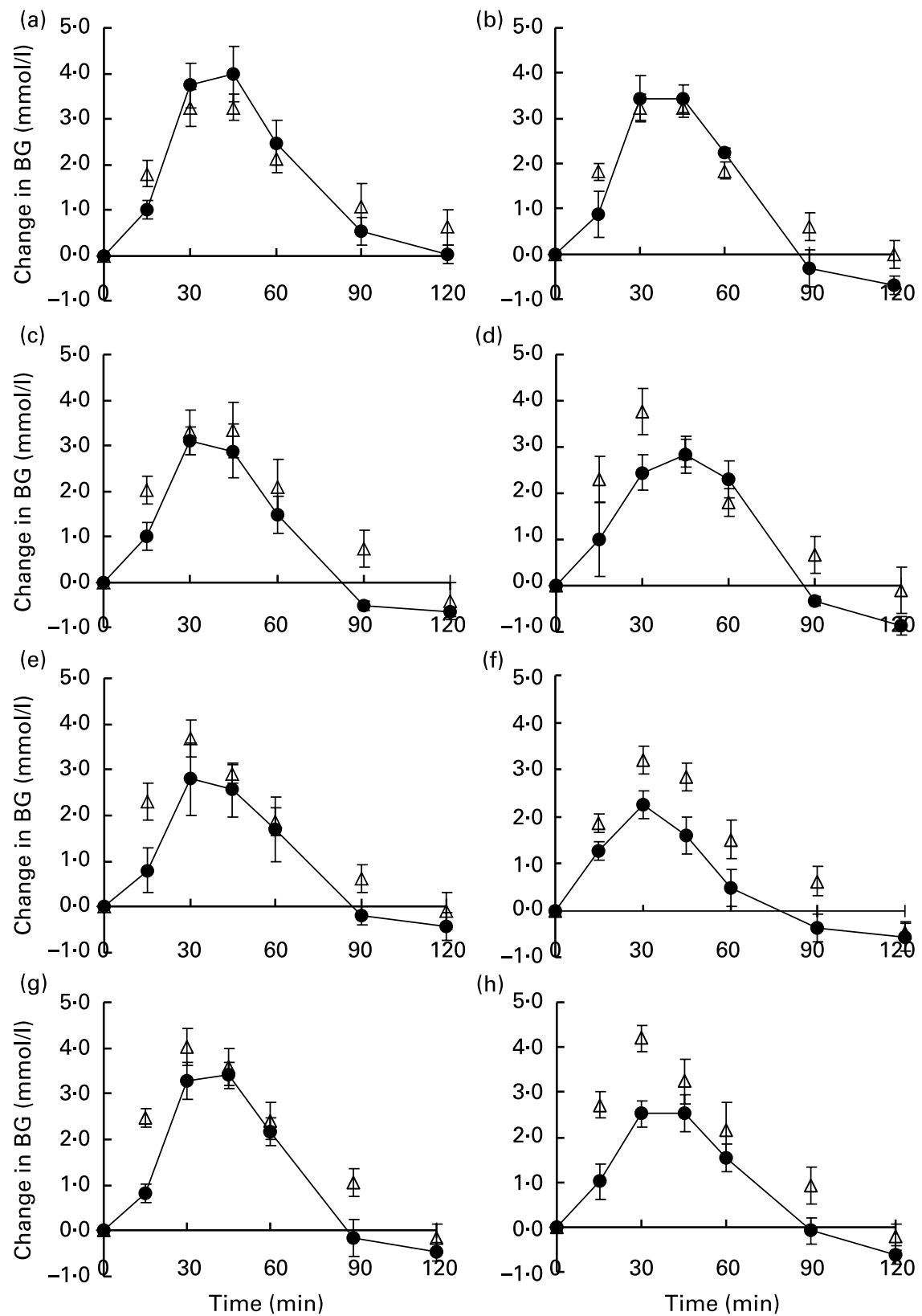

(h)

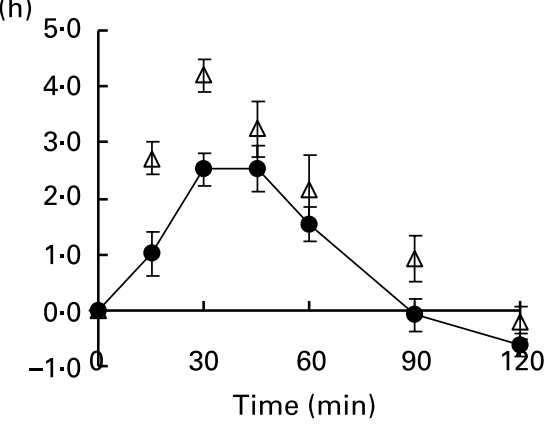

Fig. 2. Incremental area under the blood glucose curves (IAUC) for eight potato varieties ((•), (a) Maris Peer, (b) Maris Piper, (c) Desiree, (d) Estima, (e) Charlotte, (f) Marfona, (g) King Edward, (h) Nicola). $\Delta$, Glucose. For details of procedures, see p. 918. Values are the mean change in blood glucose (BG) with their standard errors represented by vertical bars $(n 10)$.

Blood was obtained by finger-prick using the Glucolet 2 multipatient lancing system (Bayer HealthCare, Newbury, Berks.). Recent reports suggest that capillary blood sampling is preferred for reliable GI testing (Food and Agriculture Organization/World Health Organization, 1998; Wolever, 2003). Prior to a fingerprick, subjects were encouraged to warm their hand to increase blood flow. Fingers were not squeezed to extract blood from the fingertip as this may dilute with plasma. Blood glucose was measured using Ascensia Contour ${ }^{\circledR}$ automatic blood glucose meters (Bayer HealthCare). The blood glucose meters were calibrated daily using control solutions from the manufacturer and were also regularly calibrated against a clinical dry chemistry analyser (Reflotron ${ }^{\circledR}$ Plus; Roche, Lewes, Sussex) and the HemoCue Glucose $201+$ analyser (HemoCue ${ }^{\circledR}$ Ltd, Angelholm, Sweden).
Figure 1 shows the Pearson regression and Bland-Altman analyses (Bland \& Altman, 1986) for a random selection of 106 blood samples simultaneously measured using the Ascensia Contour $^{\circledR}$ and the HemoCue Glucose $201+$ analyser. There was a very strong correlation $(r 0.978, P \leq 0.001)$ and good agreement (mean difference $-0.3 \mathrm{mmol} ; 95 \% \mathrm{CI}-0.3,-0.2$; limits of agreement $-0.75,0.21$ ) between blood glucose measurements using the automatic analyser and the HemoCue analyser.

\section{Calculation of glycaemic index}

The IAUC, ignoring the area beneath the baseline, was calculated geometrically for each food (Food and Agriculture Organization/ World Health Organization, 1998). The mean, standard deviation 
Table 2. Glycaemic index (GI) classification and characteristics of each potato variety

\begin{tabular}{llllc}
\hline Potato variety & Gl classification & Crop type & Texture† & $\begin{array}{r}\text { Texture } \\
\text { rating }\end{array}$ \\
\hline Maris Peer & High & Second early & Firm & 5 \\
Maris Piper & High & Main crop & Floury & 5 \\
Desiree & High & Main crop & Firm & 5 \\
Estima & Medium & Second early & Firm, moist & 4 \\
Charlotte & Medium & Salad & Firm, waxy & 4 \\
Marfona & Medium & Second early & Waxy & 3 \\
King Edward & High & Main crop & Floury & 6 \\
Nicola & Medium & Salad & Firm & 4 \\
\hline
\end{tabular}

* Information obtained from the British Potato Council website www.potato.org.uk. Texture ratings are measured on a scale from 1 to 9 ( 1 being most waxy and 9 being the most floury).

For details of procedures, see p. 918.

and CV of the IAUC of each subject's repeated standard food were calculated. The IAUC for each test product eaten by each subject was expressed as a percentage of the mean IAUC for the standard food eaten by the same subject. The GI of each potato variety was taken as the mean for the whole group.

\section{Statistical analysis}

Statistical analysis was performed using the Statistical Product and Service Solutions software version 11.0.1 (SPSS, Chicago, IL, USA). To examine the correlation and agreement between the automatic analyser and the HemoCue Glucose $201+$ analyser, Pearson's correlation coefficient and the method of Bland \& Altman (1986) were used. Levels of inter- and intra-individual variation of the three standard (glucose) tests were assessed by determining the $\mathrm{CV}$. One-way ANOVA was used to compare IAUC values and GI values between the eight potato varieties. Kendall's rank correlation coefficient (Kendall's $\tau$ ) was used to assess the relationship between GI value and potato texture rating. Statistical significance was set at $P<0 \cdot 05$.

\section{Results}

The mean $\mathrm{CV}$ of glycaemic responses to the three standard tests for the seventeen subjects was $23 \%$. The inter-individual variation in glycaemic response to the standard test for the seventeen subjects was $30 \% \mathrm{CV}$. These values are consistent with previously reported data (Wolever, 1990).

Mean IAUC and GI values for each test product are presented in Table 1 and Fig. 2. There was no significant difference in IAUC between the different potato varieties $(P=0 \cdot 188)$. The potatoes exhibited a large variation in GI values ranging from 56 (Marfona) to 94 (Maris Piper), although the differences in GI were not statistically significant $(P=0 \cdot 330)$.

For practical measures, GI values are often grouped into categories as producing either a low, medium or high glycaemic response. The cut-off values are as follows: low $\leq 55$; medium 56-69 inclusive; high $\geq 70$ (Brand-Miller et al. 2003). The GI ratings for the tested potato varieties are given in Table 2 alongside characteristics of the potato varieties. There was a strong positive correlation (Kendall's $\tau$-b $0.656 ; P=0.034$ ) between the GI value and texture rating. In general, potatoes with floury textures (low in moisture, low in sugar with high starch) were in the high-GI category, whilst those with firm to waxy textures (high in moisture, low starch) were in the medium-GI category.
Generally, the earlier crop varieties of potato (second early) and the salad potatoes tend to have waxy textures while the main crop varieties tend to have floury textures.

\section{Discussion}

The GI values reported here are comparable to those given for boiled potatoes in the recent international GI tables (Foster-Powell et al. 2002). A GI value range of 56-101 has been reported for boiled potatoes, where the type of potato has been specified, and a GI range 23-76 for unspecified potato type (Foster-Powell et al. 2002). More recently, Fernandes et al. (2005) reported a GI value of 89 for boiled red potatoes. Small differences of $<10-15$ units are within the error associated with the measurement of GI (Wolever et al. 1991; FosterPowell et al. 2002). Discrepancies may be due in part to cooking methods used, which may change the structure of the starch (Englyst \& Cummings, 1987). In particular, it has been reported that precooking and reheating potatoes before consumption will elicit a lower glycaemic response compared with potatoes consumed immediately after cooking (Fernandes et al. 2005).

The lower GI rating of firm/waxy potato varieties agrees with previous findings (Soh \& Brand-Miller, 1999). However Maris Peer, which was originally bred as a low-DM potato for use by the canning industry, is the one variety in the trial that appears to differ markedly in its GI rating (high) relative to its commercial usage as an early potato and as such may warrant further study. Changes in the nature of the starch, predominantly an increase in the amount of amylopectin (Soh \& Brand-Miller, 1999), may be partly responsible for the difference in glycaemic response seen with floury, more mature potatoes. Amylopectin has a branched structure that makes it more readily digestible than linear chain starch leading to a higher glycaemic response (Van Amelsvoort \& Westrate, 1992).

In conclusion, these results provide a comparison of the glycaemic responses of several commercially available varieties of potato. Considering the widespread consumption of potatoes in Great Britain (933-1086g per person per week), it is useful to have information regarding the glycaemic response of common varieties. The identification of potato varieties with lower glycaemic responses may help lower the GI of the British diet and potentially have benefit in the management and prevention of some chronic diseases.

\section{Acknowledgements}

This study was supported by the British Potato Council Project R256.

\section{References}

Augustin LS, Franceschi S, Jenkins DJA, Kendall CWC \& La Vecchia C (2002) Glycemic index in chronic disease: a review. Eur J Clin Nutr 56, 1049-1071.

Bjorck I, Granfeldt Y, Liljeberg H, Tovar J \& Asp NG (1994) Food properties affecting the digestion and absorption of carbohydrates. Am J Clin Nutr 59, S699-S705.

Bland JM \& Altman DG (1986) Statistical methods for assessing agreement between two methods of clinical measurement. Lancet I, 307-310.

Brand JC, Colagiuri S, Crossman S, Allen A, Roberts DCK \& Truswell AS (1991) Low-glycemic index foods improve long-term glycemic control in NIDDM. Diabetes Care 14, 95-101. 
Brand-Miller J, Foster-Powell K \& Colagiuri S (2003) The New Glucose Revolution. New York: Marlowe and Company.

Englyst HN \& Cummings JH (1987) Digestion of polysaccharides of potato in the small intestine of man. Am J Clin Nutr 45, 423-431.

Food and Agriculture Organization/World Health Organization (1998) Carbohydrates in Human Nutrition. Report of a Joint FAO/WHO Expert Consultation. Rome: FAO.

Fernandes G, Velangi A \& Wolever TMS (2005) Glycemic index of potatoes commonly consumed in North America. J Am Diet Assoc 105, 557-562.

Foster-Powell K, Holt SHA \& Brand-Miller JC (2002) International table of glycemic index and glycaemic load values: 2002. Am J Clin Nutr 76, $5-56$.

Frost G, Leeds AA, Dore CJ, Madeiros S, Brading S \& Dornhorst A (1999) Glycaemic index as a determinant of serum HDL-cholesterol concentration. Lancet 353, 1045-1048.

Frost G, Leeds A, Trew G, Margara R \& Dornhorst A (1998) Insulin sensitivity in women at risk of coronary heart disease and the effect of a low glycemic diet. Metabolism 47, 1245-1251.

Frost G, Wilding J \& Beecham J (1994) Dietary advice based on the glycaemic index improves dietary profile and metabolic control in Type 2 diabetic patients. Diabet Med 11, 397-401.

Gilbertson HR, Brand-Miller JC, Thorburn AW, Evans S, Chondros P \& Werther GA (2001) The effect of flexible low glycemic index dietary advice versus measured carbohydrate exchange diets on glycemic control in children with type 1 diabetes. Diabetes Care 24, 1137-1143.

Holt SHA, Miller JCB, Petocz P \& Farmakalidis E (1995) A satiety index of common foods. Eur J Clin Nutr 49, 675-690.

Jenkins DJA, Wolever TMS, Collier GR, Ocana A, Rao AV, Buckley G, Lam Y, Mayer A \& Thompson LU (1987b) Metabolic effects of a low glycemic index diet. Am J Clin Nutr 46, 968-975.

Jenkins DJA, Wolever TMS, Kalmusky J, et al. (1987a) Low-glycemic index diet in hyperlipidemia: use of traditional starchy foods. Am J Clin Nutr 46, 66-71.

Jenkins DJA, Wolever TMS, Taylor RH, Barker H, Fielden H, Baldwin JM, Bowling AC, Newman HC, Jenkins AL \& Goff DV (1981) Glycemic index of foods: a physiological basis for carbohydrate exchange. Am J Clin Nutr 34, 362-366.
Meyer KA, Kushi LH, Jacobs DR, Slavin J, Sellers TA \& Folsom AR (2000) Carbohydrates, dietary fiber, and incident type 2 diabetes in older women. Am J Clin Nutr 71, 921-930.

National Statistics (2004) Family Food. A Report on the 2002-03 Expenditure and Food Survey. London: TSO.

NIAB (2004) Pocket Guide to Varieties of Potato. Cambridge: NIAB.

Salmeron J, Ascherio A, Rimm EB, Colditz GA, Spiegelman D, Jenkins DJ, Stampfer MJ, Wing AL \& Willett WC (1997a) Dietary fiber, glycemic load, and risk of NIDDM in men. Diabetes Care 20, 545-550.

Salmeron J, Manson JE, Stampfer MJ, Colditz GA, Wing AL \& Willett WC (1997b) Dietary fiber, glycemic load, and risk of non-insulindependent diabetes mellitus in women. JAMA 277, 472-477.

Soh NL \& Brand-Miller J (1999) The glycaemic index of potatoes: the effect of variety, cooking method and maturity. Eur J Clin Nutr 53, 249-254.

Storey RMJ \& Davies HV (1992) Tuber quality. In The Potato Crop. The Scientific Basis for Improvement, pp. 507-569 [PM Harris, editor]. London: Chapman and Hall.

Thomas DE, Brotherhood JR \& Brand JC (1991) Carbohydrate feeding before exercise: effect of glycemic index. Int J Sports Med 12, $180-186$.

Van Amelsvoort JM \& Westrate JA (1992) Amylose-amylopectin ratio in a meal affects postprandial variables in males volunteers. Am J Clin Nutr 55, 712-718.

Warren JM, Henry CJK \& Simonite P (2003) Low glycemic index breakfasts and reduced food intake in preadolescent children. Pediatrics 112, e414-e419.

Wolever TMS (1990) The glycemic index. World Rev Nutr Diet 62, $120-185$.

Wolever TMS (2003) Carbohydrate and the regulation of blood glucose and metabolism. Nutr Rev 61, S40-S48.

Wolever TMS, Jenkins DJA, Jenkins AL \& Josse RG (1991) The glycemic index: methodology and clinical implications. Am J Clin Nutr 54, 846-854.

Wolever TMS, Jenkins DJA, Vuksan V, Jenkins AL, Buckley GC, Wong GS \& Josse RG (1992) Beneficial effect of a low glycemic index diet in Type 2 diabetes. Diabet Med 9, 451-458. 